\title{
Ampliação da jornada escolar A percepção do professor regente
}

\author{
Juliana Alves da Silva Ubinski* \\ Fernanda Aparecida Meglhioratti ${ }^{* *}$
}

\begin{abstract}
RESUMO: A ampliação da jornada escolar nos programas federais e estaduais busca contribuir com o aprendizado dos alunos e diminuir as desigualdades socioeducacionais. Porém, a ampliação do tempo de permanência na escola por si só não garante o alcance dos objetivos. É necessário ouvir os professores. Este trabalho tem por objetivo investigar a percepção dos professores regentes de atividades em contraturno na cidade de Cascavel-PR e traçar algumas reflexões acerca da implantação das atividades de ampliação de jornada escolar.
\end{abstract}

Palavras-chave: Programa Mais Educação. Ampliação da jornada. Complementação curricular em contraturno.

\section{Extension of the school day}

The teacher's perception

\begin{abstract}
The expansion of the school day in both federal and state education programs seeks to contribute to students' learning and reduce social and educational inequalities. However, extending the length of time spent in school alone does not guarantee the achievement of its objectives. We need to listen to the teachers. This paper aims to investigate the teachers' perceptions of activities in this added time, in the city of Cascavel-PR, and to draw some reflections about the implementation of the extension of the school day activities.
\end{abstract}

* Mestra em Educação pela Universidade Estadual do Oeste do Paraná (Unioeste) e especialista em Ensino de Ciências e Matemática. Atualmente está vinculada à Secretaria de Estado da Educação do Paraná. Cascavel/PR - Brasil. E-mail: <juliana_ubinski@hotmail.com>.

* Doutora em Educação para a Ciência pela Universidade Estadual Paulista Júlio de Mesquita Filho UNESP. Docente do Programa de Pós-graduação Stricto sensu em Educação da Universidade Estadual do Oeste do Paraná. Cascavel/PR - Brasil. E-mail: <meglhioratti@gmail.com>. 
Keywords: The program for more education. Extension of the working day. Extra complementary curricular activities.

\section{Ampliación del horario escolar \\ La percepción del profesor regente}

RESUMEN: La ampliación del horario escolar en los programas federales y de los estados busca contribuir al aprendizaje de los alumnos y reducir las desigualdades socioeducativas. Sin embargo, la ampliación del tiempo de permanencia en la escuela por si sola no asegura que los objetivos serán alcanzados. Es necesario escuchar a los profesores. Este trabajo tiene el objetivo de investigar la percepción de los profesores regentes de las actividades en turno extra en la ciudad de Cascavel (estado de Paraná) y esbozar algunas reflexiones sobre la implantación de las actividades de ampliación del horario escolar.

Palabras clave: Programa Más Educación. Ampliación del horario. Complementación curricular en horario extra.

\section{L'expansion de la journée scolaire}

La perception du professeur responsable

RÉSUMÉ: L'expansion de la journée scolaire dans les programmes fédéraux et d'état cherche à contribuer à l'apprentissage des élèves et à réduire les inégalités sócio-éducatives. Néanmoins, la prolongation du temps passé à l'école ne garantit pas en soi la réalisation de ces objectifs. Il est nécessaire d'écouter les professeurs. Ce travail vise à étudier la perception des professeurs responsables des activités hors temps d'études scolaires de la ville de Cascavel dans l'état du Parana et d'ébaucher quelques reflexions sur l'implantation des activités d'expansion de la journée scolaire.

Mots-clés: Programme “Plus d'éducation'. Expansion de la journée scolaire. Complément du programme scolaire dans le temps hors scolaire. 


\section{Introdução}

ampliação da jornada escolar é discutida desde o início do século XX em busca 1 de atender às diferentes demandas sociais. Contudo, programas e projetos 1 têm como obstáculos a mudança de contextos políticos, sendo, muitas vezes, desativados por "descontinuidade dos governos e por interesses políticos" (ARCO-VERDE, 2012, p. 89).

Além da dificuldade da descontinuidade dos programas implantados e da falta de tempo para o amadurecimento das ações voltadas à ampliação da jornada escolar, as políticas que se concretizam têm limitações e não contemplam todas as escolas. É fundamental investigar como são desenvolvidas as ações de ampliação do tempo escolar.

Este artigo busca uma reflexão sobre a concretização da ampliação da jornada escolar na percepção dos professores que lecionam nessas atividades no município de Cascavel-PR. Nesse contexto, algumas questões são pertinentes: Como estão acontecendo as atividades de ampliação de jornada escolar? Qual a percepção dos professores que trabalham com atividades de contraturno sobre a ampliação da jornada escolar? Ouvir os professores envolvidos na ampliação da jornada escolar é de suma importância para que se possa verificar os desafios e os avanços perceptíveis no cotidiano escolar. A pesquisa traz elementos para estimular os debates acerca do assunto e auxiliem nas decisões para fomentar melhorias na educação.

\section{Ampliação da jornada escolar}

Em 1958, Anísio Teixeira já discutia os problemas do ensino no Brasil e defendia a educação em tempo integral, propondo a organização do tempo escolar em setores, em uma das primeiras experiências de ensino com jornada escolar ampliada voltada para a classe popular. O setor 1 seria dedicado às atividades comuns de sala de aula, abrangendo os conteúdos curriculares tradicionais e o setor 2 seria destinado às atividades socializantes, tais como artes e esportes (TEIXEIRA, 1958). Para Teixeira (1962), enquanto na sala de aula convencional o aluno era preparado intelectualmente, nas escolas-parque $^{1}$ ocorreria um sentido mais completo para cada atividade.

Cavaliere e Maurício (2012) fazem uma revisão histórica sobre a educação integral e as experiências vivenciadas por Anísio Teixeira e Darcy Ribeiro. Para os autores, questões relativas ao assistencialismo dos centros educacionais que ofertavam a educação integral e a falta de recursos para atender a essa demanda culminaram na extinção precoce desses centros. Os críticos se apoiavam em argumentos, como a falta de recursos para a sua universalização, perigos do assistencialismo e inadaptação dos jovens e/ou famílias ao horário integral. Em contextos político-partidários desfavoráveis, isso 
levou ao descaso com o patrimônio público e à indiferença com a expectativa da população, resultando em prédios e projetos abandonados, escolas sem professores, alunos e famílias decepcionados.

Nas décadas de 1980 e 1990, outras experiências surgiram no Rio de Janeiro, por meio dos Centros Integrados de Educação Pública (Ciep), propostos por Darcy Ribeiro, e no âmbito nacional com os Centros de Atenção Integral à Criança (Caic) (FREITAS, 2009; CAVALIERE; MAURÍCIO, 2012). Nessa "nova" experiência, o objetivo era proporcionar aos alunos do ensino fundamental, além das atividades escolares regulares, atividades esportivas, artísticas, recreativas ou temáticas através da complementação do currículo (FREITAS, 2009). No entanto, a falta de professores qualificados para atuar na perspectiva da educação em tempo integral era uma das críticas nesse momento. Segundo Santos (2002), a qualidade da arquitetura das instalações dos centros educacionais destacavam-se mais do que a parte pedagógica.

Os esforços para a inclusão de atividades diferenciadas para complementar a formação das crianças e adolescentes ganham apoio legislativo na década de 1990, como forma de diminuir as desigualdades socioeducacionais (BRASIL, 2010a). Pode-se observar esse aspecto na lei de Diretrizes e Bases da Educação Nacional (LDB), Lei nº 9.394 (BRASIL, 1996), na qual está previsto o aumento progressivo da jornada escolar no Art. $34^{\mathrm{o}}[\ldots] \S 2^{\mathrm{o}}$ - "O ensino fundamental será ministrado progressivamente em tempo integral, a critério dos sistemas de ensino".

Em 2006, os artigos 24 e 34 da LDB foram alterados através do Projeto de lei n 234/2006 estipulando prazo de cinco anos para a instituição da jornada escolar em tempo integral (BRASIL, 2006). Em decorrência, o lançamento do Programa Federal Mais Educação (PME), instituído pela Portaria Interministerial no 17/2007 e regulamentado pelo Decreto 7.083/10, foi uma estratégia para indução da ampliação da jornada escolar.

Além do Programa Federal Mais Educação, alguns estados têm propostas próprias para a ampliação da jornada escolar que recebem diferentes denominações como: mais tempo na escola, bairro escola, mais tempo para a qualidade, Super Escola e Escola Viva (BRASIL, 2009). No Paraná, o programa destinado à ampliação da jornada escolar é denominado Atividades de Complementação Curricular em Contraturno.

Como o foco de estudo desse artigo são as atividades de ampliação de jornada escolar que ocorrem no município de Cascavel-PR, detalhamos os dois programas que fundamentam as ações no munícipio: O Programa Federal Mais Educação e o Programa Paranaense de Complementação Curricular. 


\section{Programas de ampliação da jornada}

O Programa Mais Educação (PME/BRASIL, 2007) é constituído mediante uma ação integrada entre políticas públicas educacionais e políticas sociais. A estratégia é a promoção da "ampliação de tempos, espaços, oportunidades educativas e o compartilhamento da tarefa de educar entre os profissionais da educação e de outras áreas" (BRASIL, 2014a, p.4), além de envolver a família e a comunidade, sob a coordenação e orientação da escola.

As escolas selecionadas para participar do PME, precisam destinar espaços para que os alunos inseridos nas atividades tenham, no mínimo, uma jornada escolar diária de sete horas/aula ou de 35 horas/aula por semana (BRASIL, 2014b). No estado do Paraná, as orientações para as escolas vinculadas ao PME é que haja ampliação de três horas-aula diárias com trinta minutos de intervalo orientado. As escolas recebem verba para aquisição de materiais e alimentação para os alunos incluídos no programa.

A preocupação em unir a sociedade e o poder público em prol da melhoria na educação é evidenciada nas orientações do PME. Porém, destaca-se que as atividades precisam ser envolventes para que os alunos sejam estimulados a participar do projeto. As possibilidades para proposição de atividades estão organizadas por áreas denominadas macrocampos (BRASIL, 2014b): acompanhamento pedagógico; comunicação, uso de mídias e cultura digital e tecnológica; cultura, artes e educação patrimonial; educação ambiental, desenvolvimento sustentável e economia solidária e criativa/educação econômica (educação financeira e fiscal); esporte e lazer; educação em direitos humanos; promoção da saúde (BRASIL, 2014b). Portanto, as escolas têm uma gama de temáticas para direcionar suas atividades de modo a contemplar a realidade da comunidade local bem como as necessidades socioeducacionais dos alunos. O PME preocupa-se também com a proteção social (BRASIL, 2009, p. 22), considerando-a uma das atribuições da escola.

No Paraná, no ano de 2008, foi aprovado o programa de ampliação da jornada escolar denominado programa de Atividades de Complementação Curricular em Contraturno Viva a Escola (PARANÁ, 2008), tendo como referência a mesma legislação utilizada para a elaboração das orientações do PME.

Com a mudança na gestão do governo paranaense, no ano de 2010, o termo Viva a Escola foi suprimido, o programa passou a ser denominado somente programa de Atividades de Complementação Curricular em Contraturno (ACCC). Embora não faça referências ao Programa Mais Educação ou à legislação federal que regulamenta a ampliação, nem a legislação estadual aprovada na gestão anterior, o programa ACCC fez uma junção dos dois programas com algumas poucas adaptações. Os objetivos definidos para as ACCC a partir de 2010 foram:

Promover a melhoria da qualidade do ensino por meio da ampliação de tempos, espaços e oportunidades educativas realizadas em contraturno, na escola 
ou no território em que está situada, a fim de atender às necessidades socioeducacionais dos alunos;

Ofertar atividades complementares ao currículo escolar vinculadas ao Projeto Político-Pedagógico da Escola, respondendo às demandas educacionais e aos anseios da comunidade;

Possibilitar maior integração entre alunos, escola e comunidade, democratizando o acesso ao conhecimento e aos bens culturais (PARANÁ, 2010, p.3).

O programa ACCC objetiva o "empoderamento educacional dos sujeitos envolvidos por meio do contato com os conhecimentos, equipamentos sociais e culturais" (PARANÁ, 2010, p. 3) a partir da ampliação da jornada escolar. As atividades previstas, assim como ocorre no PME, estão organizadas por macrocampos: aprofundamento da aprendizagem; experimentação e iniciação científica; cultura e arte; esporte e lazer, tecnologias da informação, da comunicação e uso de mídias; meio ambiente; direitos humanos; promoção da saúde; mundo do trabalho e geração de rendas. Embora com denominações e organização diferentes, os macrocampos definidos pelo programa de ACCC, assemelham-se aos macrocampos definidos no PME.

A proposta do PME é semelhante ao idealizado por Anísio Teixeira (1958) quanto à organização da jornada escolar em dois turnos, sendo um turno voltado para os conteúdos escolares e outro destinado a atividades voltadas para aprofundamento e aplicação dos conteúdos em situações da realidade dos alunos. No entanto, Teixeira (1958) idealizou a estrutura das escolas para atender a demanda da ampliação da jornada escolar, enquanto o PME não define uma estrutura mínima para que as atividades aconteçam. Por outro lado, o Brasil (2014b) prevê a realização de parcerias entre escolas e sociedade para a realização das atividades em outros ambientes, para os casos de escolas que tenham interesse em realizar as atividades e não tenham espaços físicos condizentes com as necessidades das atividades ofertadas.

Embora a busca por espaços fora da escola para realização das atividades possa ser uma estratégia a fim de suprir a carência de estrutura da escola, Cavaliere (2007) menciona a falta de referência para alunos e professores na realização das atividades fora do ambiente escolar. Nesse caso, a escola precisa estar bem estruturada para descentralizar as atividades ofertadas, sem comprometer os processos de planejamento e avaliação.

Assim como em experiências anteriores, a ampliação da jornada escolar busca por uma formação mais abrangente e articulada com o cotidiano do aluno e contribuir para a diminuição das desigualdades educacionais (BRASIL, 2010b). Uma das formas de saber se as atividades estão se aproximando dos objetivos é conhecer a opinião daqueles que estão à frente delas nas escolas: os professores. 


\section{Aspectos metodológicos da pesquisa}

A cidade de Cascavel-PR contempla 37 escolas estaduais que atendem alunos dos anos finais do ensino fundamental, ensino médio, profissionalizante, educação de jovens e adultos e educação no campo. Destas escolas, 85\% estão vinculadas ao programa de ACCC e/ou PME. O percentual de escolas que ofertam algum tipo de atividade de ampliação da jornada escolar na cidade é significativo, sendo a partir desses dados que a pesquisa foi idealizada e realizada.

Através da análise dos dados dos dois programas, fornecidos pelo Núcleo Regional de Ensino de Cascavel, foi possível mapear as áreas de interesse das 93 atividades propostas para o contraturno referentes ao ano de 2014, sendo 33 vinculadas ao PME e 60 vinculadas ao programa ACCC.

No mapeamento das atividades ofertadas em Cascavel-PR foi possível perceber a prevalência de atividades na área de Arte e Cultura, com 47,31\%, aprofundamento de aprendizagem, com 23,65\%, e atividades esportivas, com 19,35\%. As atividades voltadas ao aprofundamento da aprendizagem são obrigatórias no PME. Além das atividades esportivas vinculadas aos programas analisados, há ainda o Programa Hora-treinamento, que também oferta atividades esportivas em contraturno. Outras atividades ofertadas foram: Ambiente/Educação Ambiental (9,67\%), Comunicação e Mídias (3,22\%), Iniciação e Experimentação Científica (3,22\%), Mundo do Trabalho e Geração de Emprego (2,25\%), Promoção da Saúde (2,15\%), Direitos Humanos (1,07\%).

A amostra da pesquisa foi composta por $15 \%$ das escolas que ofertaram atividades de ampliação da jornada escolar no ano de 2014, ou seja, cinco escolas. Os professores responsáveis pelas atividades foram entrevistados com o objetivo de investigar sua percepção sobre a concretização das atividades e dos programas de ampliação de jornada escolar. As atividades de complementação privilegiadas foram na área de Educação Ambiental, sendo possível realizar um comparativo entre as escolas através de atividades de um mesmo macrocampo. As entrevistas foram precedidas pela autorização da realização da pesquisa pelo Comitê de Ética da Universidade Estadual do Oeste Paraná, bem como pelo aceite de participação na pesquisa através da leitura e assinatura do Termo de Consentimento Livre Esclarecido (TCLE).

O Quadro 1 apresenta as escolas participantes da pesquisa, o Índice de Desenvolvimento da Educação Básica (Ideb) e os programas de ampliação de jornada escolar vinculados a cada escola. 


\section{Quadro 1 - Composição da Amostra: Perfil das escolas}

\begin{tabular}{|c|l|c|l}
\hline COD & Ensino ofertado & IDEB & Programa \\
\hline E01 & Médio e Profissionalizante & 5,0 & $\begin{array}{l}\text { Atividade de Complementação Curricular } \\
\text { em Contraturno (Estadual) }\end{array}$ \\
\hline E02 & Fundamental e Médio & 3,9 & $\begin{array}{l}\text { Atividade de Complementação Curricular } \\
\text { em Contraturno (Estadual) }\end{array}$ \\
\hline E03 & Fundamental e Médio & 3,5 & Programa Mais Educação (Federal) \\
\hline E04 & Fundamental e Médio & 3,3 & Programa Mais Educação (Federal) \\
\hline E05 & Fundamental e Médio & 3,5 & Programa Mais Educação (Federal) \\
\hline
\end{tabular}

Fonte: Dados da pesquisa (2014).

As escolas E03, E04 e E05 têm índice do Ideb contemplado pelo PME, que preconiza atender escolas com Ideb menor do que 3,9 nos anos finais do ensino fundamental, podendo ser esse o motivo de as três escolas estarem vinculadas ao programa. $\mathrm{O}$ vínculo ao programa depende da disposição e condições da escola, já que demanda espaço físico para a realização das atividades (BRASIL, 2014b). As escolas E01 e E02 têm Ideb superior ao preconizado para as escolas participantes do PME, podendo ser este o motivo da opção para participação do programa estadual ACCC. No Quadro 2 está apresentado o perfil dos professores regentes das atividades que compõem a amostra da pesquisa.

\section{Quadro 2 - Composição da Amostra: Perfil dos Professores}

\begin{tabular}{|c|l|c|c}
\hline COD & Formação & $\begin{array}{c}\text { Experiência em } \\
\text { jornada ampliada }\end{array}$ & Tipo de vínculo \\
\hline E01 & Ciências Biológicas + Especialização & 8 anos & Efetivo \\
\hline E02 & Ciências Biológicas + Especialização & 1 Ano & Temporário \\
\hline E03 & História + Especialização & 1 Ano & Temporário \\
\hline E04 & Ciências Biológicas + Especialização & 1 Ano & Temporário \\
\hline E05 & Ciências Biológicas + Especialização & 1 Ano & Temporário \\
\hline
\end{tabular}

Fonte: Dados da pesquisa (2014).

A entrevista com os professores foi audiogravada e realizada a partir de um roteiro semiestruturado. Segundo Triviños (1987), a entrevista semiestruturada possui como característica a presença de perguntas básicas, com apoio em teorias e/ou hipóteses relacionadas ao tema da pesquisa. As perguntas podem gerar novas hipóteses a partir das respostas do entrevistado, sendo o foco principal alocado pelo pesquisador-entrevistador. Para o autor, este tipo de entrevista “[...] favorece não só a descrição dos fenômenos 
sociais, mas também sua explicação e a compreensão de sua totalidade [...]" (TRIVIÑOS, 1987, p. 152). Para a realização da entrevista semiestruturada é necessária a definição de um roteiro que aborde as principais questões da pesquisa, porém, que permita certa flexibilidade ao pesquisador para obter as informações necessárias.

\section{Análise e discussão dos dados}

Os professores foram questionados sobre vários aspectos do programa a que a atividade de sua atuação estava vinculada. Neste trabalho, privilegiou-se a percepção dos professores em relação aos principais desafios e resultados.

O primeiro desafio se configura antes mesmo da atividade iniciar, pois a distribuição das aulas relacionadas aos projetos aprovados é realizada após o início do ano letivo, comumente no mês de março. Nessa época, os professores efetivos já assumiram aulas, sendo assim, cabe a professores temporários assumir as aulas relacionadas às atividades em contraturno. Desta forma, os professores que assumem as aulas podem não conhecer a realidade da comunidade escolar em que a atividade está inserida, além de assumir uma atividade que não contou com sua participação na definição da temática.

As atividades em contraturno que compõem a amostra da pesquisa foram propostas pela escola, não sendo possível evidenciar na entrevista o responsável pelo envio. Apenas em uma das atividades há presença de um mesmo profissional, desde a idealização da atividade, em 2011.

[...] quando surgiu a ideia do projeto a diretora [...] me chamou na época pediu sugestão de um projeto para o curso técnico de meio ambiente no caso e para mim parecia bastante óbvio a questão dos resíduos sólidos (PROFESSOR E01, 2014).

Nas demais atividades, os professores assumiram as aulas em atividades já escritas e aprovadas, e nesses casos não souberam dizer como foram escolhidas as temáticas e nem quem escreveu as propostas.

[...] quando eu cheguei, eles já me apresentaram a escola que fez o projeto, o nome do projeto é horticultura e paisagismo, daí, foi a escola que desenvolveu o projeto e me apresentou (PROFESSOR E05, 2014).

Tanto no programa federal quanto no estadual não estão definidos os requisitos mínimos exigidos para que o professor assuma as atividades em contraturno. Apenas no caso dos monitores há previsão de que sejam, preferencialmente, acadêmicos de cursos de licenciatura com vínculo ao Programa Institucional de Bolsa de Iniciação à Docência (Pibid) ou estudantes de graduação com estágio supervisionado (BRASIL, 2014b). Assim, os professores que assumem as atividades não têm previamente conhecimento 
sobre a proposta escrita, podendo não ter o conhecimento mínimo para realizar a atividade docente de forma a contribuir com o alcance dos resultados.

[...] eu sou da área de história, mas é meio ambiente e sustentabilidade [...] daí o pessoal acha "mas você sabe fazer isso", não, eu não sei fazer isso [...] eu fico completamente perdida, todas as áreas acho que eu poderia explorar, acho que já foram exploradas, eu já não tenho mais pra onde ir (PROFESSOR E04, 2014).

Sendo assim, os professores correm o risco de se ater ao conhecimento do senso comum, sem uma aproximação maior com o conhecimento científico. Sem domínio da temática ejá tendo assumido a atividade, o professor precisa ir à busca do conhecimento necessário, nem sempre em fontes confiáveis.

[...] então lá na minha cidade mesmo eu procurei alguém que tinha horta falei mais ou menos como que era aí a pessoa meio que me orientou [...] aí eu fui procurar ler na internet (PROFESSOR E03, 2014).

Outra questão é a falta de conhecimento sobre o funcionamento dos programas em que está inserido, o que pode levar o professor a se perder durante a realização das atividades. Ao contrário do que ocorre no ensino regular, os programas não possuem uma diretriz por macrocampo para orientar o professor, já que a ideia é dar liberdade para que a escola possa adequar a temática e atender a demanda da comunidade escolar e comunidade local (BRASIL, 2014b). Nesse contexto, a capacitação de professores para atuação nestes programas seria de grande valia para diminuir a insegurança frente às atividades.

[...] eu vou ser bem sincera às vezes eu tenho pânico quando entro no mais educação, porque todo mundo falava "ai o mais educação é legal e bom porque não tem avaliação", mas é eu não sei se é uma falha minha de gostar de ter um sistema que que pelo menos te orienta [...] aqui você não tem no mais educação, você não tem orientação nenhuma, é assim faça o que você quiser (PROFESSOR E04, 2014).

A questão da verba também foi abordada pelos professores, exceto em E01. O professor E02 mencionou a dificuldade em realizar atividades diferenciadas, já que o programa estadual não destina verba para aquisição de materiais. Os professores de E03, E04 e E05 destacaram a dificuldade de iniciar as atividades, já que o Governo Federal atrasou o repasse da verba. Neste sentido, a aquisição de materiais necessários para a realização das atividades foi comprometida.

Dentre os cinco professores ouvidos, apenas um tinha experiência anterior com a atividade. Fica evidente que a rotatividade do professor no contraturno ocorre com frequência, interferindo na superação de problemas metodológicos e outras melhorias que poderiam ser realizadas no caso de sua permanência. Quatro professores mencionaram que algumas ações realizadas em 2014 seriam revistas caso eles assumissem a 
atividade novamente no ano de 2015, porém, nessas quatro atividades havia outros professores em 2015.

Quero (continuar na atividade no ano que vem) porque esse ano foi uma aprendizagem, eu posso dizer [...] tem muitas ideias ainda do que pode ser feito sabe (PROFESSOR 04, 2014).

Para os professores o primeiro ano à frente da atividade serviu de aprendizado/ experiência, por isso demonstram interesse em estar à frente no ano seguinte.

[...] este primeiro ano serviu também como um aprendizado, então tiveram uns erros que aconteceram neste ano que já conseguiria trabalhar melhor com eles, mas aí entra a questão da rotatividade do PSS² e tudo mais. O padrão geralmente não consegue pegar essas aulas de projeto no início por ter já uma carga horária fechada e quer abandonar turmas para poder pegar e tudo mais, porque geralmente o projeto não abre logo no início do calendário, ele abre posteriormente, então aí quem acaba pegando é PSS e PSS que tem bastante rotatividade, que um ano está aqui, outro ano está lá ou não vai conseguir pegar aula (PROFESSOR E02, 2014).

A forma como ocorre a distribuição das aulas relacionadas com as atividades em contraturno contribui para a rotatividade de professores e, consequentemente, com rupturas e reinícios, especialmente no aspecto metodológico. Manter um profissional a frente da atividade, desde o início, acaba contribuindo para que a atividade em contraturno ganhe forma, e vá atingindo e superando os resultados esperados. Atualmente, a escola E01, que apresenta continuidade do professor responsável, por exemplo, é reconhecida como um ponto de coleta para diversos tipos de resíduos, nos quais se destacam os eletrônicos. A atividade ofertada atinge os alunos, a comunidade escolar, a comunidade do entorno e moradores de bairros mais afastados.

As demais atividades apresentam rotatividade de professores, pois, ao contrário do que ocorre em E01, onde há um profissional efetivo desde a idealização, nas demais os professores são temporários, sendo incerta sua participação no ano seguinte.

Quanto à frequência dos alunos, variava entre 20 e 25 alunos, em E01, E03 e E05. Em E02 uma média de 12 alunos estava participando, e em E04 apenas cinco alunos. A orientação da Secretaria de Estado do Paraná (Seed) é que no caso de desistência de alunos participantes sejam matriculados outros alunos (PARANÁ, 2014), no entanto, as escolas que não seguem essa orientação não podem ser penalizadas, já que haveria diferenciação no nível de aprendizagem entre os alunos que estão integrados na atividade desde o início do ano e aqueles que começam a participar no final do ano.

Quando questionados sobre os conteúdos abordados durante as atividades em contraturno, bem como a aprendizagem dos alunos, os professores mostraram confiança em relação à efetividade da proposta. Os professores elencaram alguns dos conteúdos abordados no decorrer da atividade: 
[...] nutrientes, germinação, tipos de hortaliças [...] ciclo de vida na horta [...] reciclagem (PROFESSOR E04, 2014).

A sustentabilidade [...] como a questão da redução do consumo [...] a questão do não imediatismo [...] ciclo de vida [...] questão de redução de lixo de resíduos sólidos (PROFESSOR E02, 2014).

A partir dos conteúdos abordados, os professores tiveram a oportunidade de testemunhar mudanças de comportamento dos alunos ou ouvir relatos de mudança de hábito.

[...] está consumindo bem mais folhas de casa, a gente está produzindo mais folhas, ninguém está consumindo do mercado [...] antes optavam por comprar mais salgadinho (PROFESSOR E02, 2014).

A gente trabalhou reciclagem, nisso eu vi uma mudança bem radical, eles eram muito relaxados nessa parte [...] chupavam uma bala e jogavam papel no chão [...] então eu trabalhei bastante essa parte sabe [...] até a gente estava lá às vezes na horta, lá limpando, tirando o mato, e no começo eles jogavam papel no chão, então isso eu consegui eliminar, sabe, foi boa a mudança (PROFESSOR E04, 2014).

As atividades em contraturno permitem ao professor maior convivência com os alunos, possibilitando ao professor ouvir os relatos e observar as mudanças de postura no decorrer do ano.

\section{Considerações finais}

Embora possa ser uma importante ação para diminuir as desigualdades socioeducacionais, a complementação curricular ou educação em tempo integral precisa ser constantemente avaliada para verificar como ela está ocorrendo, quais os resultados alcançados e quais as dificuldades encontradas pelos professores.

$\mathrm{Na}$ análise desenvolvida neste artigo é possível observar que a rotatividade do professor foi um problema para o desenvolvimento e aprofundamento das atividades de ampliação de jornada escolar. Há que garantir a continuidade dos professores nas atividades. Em um cenário ideal, deveriam ser assumidas por professores efetivos, contudo, mesmo que isso não ocorra, a distribuição de aulas deveria criar mecanismos que priorizassem a continuidade do docente que elaborou a atividade no decorrer dos anos. A permanência do professor facilitaria a discussão com a comunidade escolar e a inclusão das necessidades indicadas pelos alunos em relação à aprendizagem e vivência das propostas desenvolvidas. Além disso, a permanência proporcionaria a reflexão dos resultados alcançados e o replanejamento das propostas, de modo a superar os obstáculos iniciais e os problemas que aparecem. 
Outro ponto que se destacou na análise das falas dos professores entrevistados foi a necessidade de investimento em infraestrutura e recursos humanos. Uma infraestrutura de qualidade permite ao professor a realização de diferentes abordagens metodológicas, sem ônus para ele. Contudo, é ainda mais fundamental o investimento em recursos humanos para gerir e desenvolver as atividades de ampliação de jornada escolar. Essa adequação de recursos humanos inicia-se pelo estabelecimento de requisitos mínimos para que um professor possa assumir a atividade em determinada temática. É importante também que os professores que assumam as atividades tenham conhecimento dos programas de ampliação de jornada escolar em que estão envolvidos; desse modo, os núcleos regionais de educação poderiam orientar grupos de estudos e reuniões de planejamento específico para o desenvolvimento dessas atividades.

As atividades analisadas apresentaram uma série de obstáculos na visão dos professores responsáveis. Todavia, mesmo com dificuldades, os professores perceberam aspectos positivos da ampliação do tempo de permanência dos alunos na escola, como o cuidado com o ambiente escolar (não jogar papeis no chão e separar os resíduos para descarte) e maior atenção com a alimentação (diminuição do consumo de salgadinhos e maior ingestão de legumes e verduras).

Ao apresentar a percepção dos professores sobre o desenvolvimento das atividades em contraturno, construiu-se alguns indicativos para o melhor aproveitamento do tempo escolar no aprendizado do aluno. Entre os indicativos centrais estão a necessidade de participação do docente, desde a proposição da atividade até seu desenvolvimento e replanejamento e a formação profissional adequada para atuar. Considera-se que compreender as dificuldades que os programas de ampliação de jornada possuem permite rever as ações que não estão alcançando resultados significativos na aprendizagem dos alunos e, assim, caminhar para ações que promovam avanços na educação brasileira.

Recebido em 15/02/2016, reapresentado em 23/02/2016 e aprovado em 03/03/2016

\section{Notas}

1 É o conjunto de edifícios de atividades de trabalho, sociais, de educação física e de arte.

2 PSS são denominados os profissionais temporários contratados pelo Processo Seletivo Simplificado que ocorre todos os anos no estado do Paraná. 


\section{Referências}

ARCO-VERDE, Yvelise Freitas de Souza. Tempo escolar e organização do trabalho pedagógico. Em Aberto, Brasília, v. 25, n. 88, p. 83-97, jul./dez. 2012.

BRASIL. Casa Civil. Diretrizes e bases da Educação Nacional. Lei 9.394 de 20 de Dezembro de 1996.

Diário Oficial. Disponível em <http://www.planalto.gov.br/CCIVIL_03/leis L9394.htm> Acesso: 11 de Novembro de 2014.

BRASIL. Ministério da educação. Educação integral/educação integrada e(m) tempo integral: concepções e práticas na educação brasileira - mapeamento das experiências de jornada escolar ampliada no Brasil: estudo qualitativo. 2009. Disponível em: <https://www.ufmg.br/online/arquivos/ anexos/pesquisa_educacao.pdf $\geq$. Acesso em 15 de novembro de 2015.

BRASIL. Senado Federal. Projeto de lei do senado № 234/2006. Diário Oficial. Disponível <http:// www.portaldocomercio.org.br/SipD/default.aspx?arquivo=82 10\&id=32115> Acesso: 11 de Novembro de 2014.

BRASIL. Ministério da Educação. Portaria Normativa Interministerial №- 17, de 24 de Abril de 2007. Diário Oficial. Disponível em <http://portal.mec.gov.br/arquivos/ pdf/mais_educacao.pdf> Acesso: 10 de Novembro de 2014.

BRASIL. Casa Civil. Decreto No 7.083 de 27 de Janeiro de 2010a: Programa Mais Educação. Diário Oficial. Disponível em < http://www.planalto.gov.br/ ccivil_03 /_ato2007-2010/2010/decreto/d7083. $\mathrm{htm}>$ Acesso: 11 de Novembro de 2014.

BRASIL. Casa Civil. Programa Mais Educação. Decreto № 7.083, de 27 De Janeiro de 2010b._Diário Oficial. Disponível em <http://www.planalto.gov.br/ccivil_03/_ato2007-2010/2010/decreto/ d7083.htm> Acesso: 20 de março de 2014.

BRASIL. Ministério da Educação. Programa Mais Educação. Brasília, DF, Ano 2014a, 171p. Disponível em <http://portal.mec.gov.br/index.php?option=com_ content\&view=article\&id=16690 \&Itemid=1115> Acesso: 10 de Julho de 2014.

BRASIL. Ministério da Educação. Manual Operacional da Educação Integral. Brasília, DF. 2014b Disponível em: $<$ http://portal.mec.gov.br/index.php?option= com_content\&view=article\&id =1669 0 \&Itemid=1115>. Acesso: 10 de Julho de 2014.

BRASIL. Secretaria de Educação Continuada. Educação integral: texto referência para o debate nacional. - Brasília : Mec, Secad, 2009. 52p.

CAVALIERE, Ana Maria. Tempo de escola e qualidade na educação pública. Educação \& Sociedade. Campinas, vol. 28, n. 100 - Especial, p. 1015-1035, out. 2007.

CAVALIERE, Ana Maria; MAURÍCIO, Lucia Velloso. A ampliação da jornada escolar nas regiões Nordeste e Sudeste: sobre modelos e realidades. 2012. Disponível em <http://luciavelloso.com.br/ arquivo/publicacoes/artigo01.pdf> Acesso: 10 de Maio de 2014.

FREITAS, Elaine Domingues da Silva. Sistema de ensino integral: qualidade ou quantidade? Dissertação (Mestrado), Fundação Cesgranrio, Rio de Janeiro, 2009.

PARANÁ. Secretaria de Estado de Educação. Programa Viva a Escola. Instrução. N.o 017/08. SUED/ SEED. 2008. Diário Oficial. http://www.educacao.pr.gov.br/arquivos/File/instrucoes/instrucao172008. PDF 
PARANA. Secretaria de Estado da Educação. Instrução 003/2010. Atividades de Complementação Curricular do Programa Viva Escola e Mais Educação na documentação escolar. Diário Oficial. 2010. Disponível em <http://www.educacao .pr.gov.br/arquivos/File/instrucoes/instrucao032010.pdf > Acesso Julho de 2015.

PARANÁ. Secretaria Estadual de Educação. Programa Mais Educação. Ofício Circular № 04/2014 SUED/DEB. Curitiba, 28 de Fevereiro de 2014.

SANTOS, D. Síntese teórica e práticas pedagógicas: texto final. Florianópolis: SEED,2002.

TEIXEIRA, Anísio. Fraude contra a educação popular. Leitura. Rio de Janeiro, v.16, n.10, abr. 1958. p.32-33.

TEIXEIRA, Anísio. Uma experiência de educação primária integral no Brasil. Revista Brasileira de Estudos Pedagógicos. Rio de Janeiro, v.38, n.87, jul./set. 1962. p.21-33.

TRIVIÑOS, Augusto Nibaldo Silva. Introdução à pesquisa em ciências sociais: a pesquisa qualitativa em educação. São Paulo, Atlas, 1987. 175p. 